\title{
Effectiveness of Trigger Point Dry Needling on Lumbosacral Radiculopathy among Indian Homemakers: A Randomized Controlled Trial
}

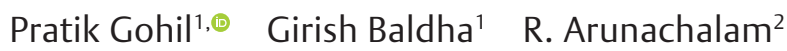 \\ ${ }^{1}$ Department of Physiotherapy, Madhav University, Sirohi, \\ Rajasthan, India \\ ${ }^{2}$ College of Physiotherapy, Madhav University, Sirohi, Rajasthan, India
}

\begin{abstract}
Address for correspondence Pratik Gohil, PhD Scholar, Department of Physiotherapy, Madhav University, Opposite Banas River Bridge Toll, N.H.-27, P.O. Bharja, Abu Road, Pindwara, Sirohi 307026, Rajasthan, India (e-mail: drpratik88@gmail.com).
\end{abstract}

Ann Natl Acad Med Sci (India) 2021;57:232-236.

\begin{abstract}
Keywords

- Indian housemaker

- lumbosacral radiculopathy

- needle therapy

- sciatica

- trigger point dry needling

Background and Aim Lumbosacral radiculopathy is a typical disorder among people belonging to diverse populations. Myofascial trigger points are commonly located on the lumbar and pelvic girdle areas, which are known for aggravating pain in lumbar radiculopathy. This study was conducted to know the effectiveness of trigger point dry needling on lumbosacral radiculopathy among Indian homemakers in pain.

Methods One hundred subjects between the age group of 40 to 60 years clinically diagnosed with lumbosacral radiculopathy associated with myofascial trigger points were screened, and 40 subjects who matched the inclusion criteria were enrolled to study after ethical approval. Subjects were randomly allocated into group A $(n=20)$ (experimental/trigger point dry needling) and group B ( $n=20$ control/sham needle therapy) for five sessions in a week. Outcomes were measured using a numerical pain rating scale for pain.

Results The level of significance was determined by $p<0.05$ at $95 \%$ confidence interval. Statistically, significant improvements were seen between the mean pre- and postscores of both the groups $(p<0.05)$. However, the reduction in mean pain scores was statistically more significant in group A (decrease by $65.7 \%$ ) than group $B$ (decrease by $14.1 \%)$.

Conclusion Trigger point dry needling on lumbosacral radiculopathy provided to group A was more effective than intervention provided to group B control study participants.
\end{abstract}

\section{Introduction}

Lumbosacral radiculopathy is a typical condition predominantly observed within individuals of various populations. Prevalence is estimated to be 3 to $5 \%$ of the population, affecting both men and women. ${ }^{1}$

Age is the main culprit as it is associated with spinal degeneration. ${ }^{2}$ Symptoms which include lower back pain

published online October 26, 2021
DOI https://doi.org/ $10.1055 / \mathrm{s}-0041-1739035$ ISSN 0379-038X associated with radiculopathy commonly start appearing in middle age or later. ${ }^{3}$

Lumbosacral radiculopathy presents with dermatomal pain due to compression of the nerve root, and weakness and paresis of the muscle groups, and can be diagnosed with a positive straight leg raise (Lasègue) test. ${ }^{4}$

Many studies have confirmed that trigger points are common sources of regional neuromusculoskeletal pain. ${ }^{5}$ (c) 2021. National Academy of Medical Sciences (India).

This is an open access article published by Thieme under the terms of the Creative Commons Attribution-NonDerivative-NonCommercial-License, permitting copying and reproduction so long as the original work is given appropriate credit. Contents may not be used for commercial purposes, or adapted, remixed, transformed or built upon. (https://creativecommons.org/licenses/by-nc-nd/4.0/).

Thieme Medical and Scientific Publishers Pvt. Ltd. A-12, 2nd Floor, Sector 2, Noida-201301 UP, India 
Trigger points are commonly seen in radiculopathy, which is a major reason for pain aggravation. ${ }^{6}$

Trigger points are discrete, focal, and hyperirritable spots located in a taut band of skeletal muscle. Acute trauma or repetitive microtrauma may lead to the development of stress on muscle fibers and the formation of trigger points. Palpation of the trigger point will elicit pain directly over the affected area and/or cause radiation of pain toward a zone of reference and a local twitch response. ${ }^{7}$

Studies have shown that that one needs to attend trigger point first in patients suffering from chronic lumbosacral radiculopathy, as it can significantly improve their recovery, and only conservative therapy may not be adequate. ${ }^{8}$

Various modalities, pharmacological agents, manual and physical therapy, dry needling, trigger point injections, and botulinum toxin injections have been widely used for the treatment of trigger points. ${ }^{9}$

Dry needling is an invasive technique used by physical therapists in an attempt to inactivate trigger points by inserting needles. In 2009, the American Physical Therapy Association (APTA) recommended "intramuscular therapy (IMT)" as the term to be used by physical therapists to describe the intervention of dry needling. ${ }^{10}$

Out of many methods of pain modulation, dry needling is becoming very popular among young physiotherapists. Although it is within the scope of physiotherapist practice with efficacy and low risk, questions remain as to its effectiveness and safety. ${ }^{11}$

Many physical therapists view dry needling as a tool of short-term improvement but studies have conformed to the long-lasting benefits of dry needling in many conditions like lateral epicondylitis. ${ }^{12}$

This study is to establish a combined effect of dry needling along with electrical stimulation as it has shown great outputs in many musculoskeletal injuries. So, this study aimed to determine the effectiveness of trigger point dry needling on lumbosacral radiculopathy and evaluate the effect of trigger point dry needling on patient's pain scores by nullifying the placebo factor.

\section{Methods}

Ethical clearance was obtained from the Institutional Ethics Committee at the institute where the study was conducted. One hundred female patients clinically diagnosed with lumbosacral radiculopathy associated with myofascial trigger points were screened for the study. Indian female homemakers aged between 40 to 60 years with lumbar radiculopathy < 3 months, associated with positive straight leg raise test, tingling sensation to anyone leg along, with active trigger points in the lower back and pelvic girdle area were included in the study. ${ }^{13}$

Any individual with a history of spine surgery, malignancy, fracture in spine/pelvic area, nonwillingness for needle therapy, presence of any red flags for lumbar spine like cauda equine, etc. was excluded from the study. Also, patients who had motor deficits (on manual muscle testing motor power less than $3 / 5$ ) and absence of knee/ankle jerk were excluded from the study. Patients who fulfilled our inclusion and exclusion criteria were taken for a double-blinded study (duration of study: January 1, 2020 to December 31, 2020).

Written informed consent was taken and there was no dropout in the study.

The subjects were randomly allocated to two groups by systemic sampling technique. Here, sample size was calculated by the formula given by Daniel. ${ }^{14}$

Group A ( $n=20)$ received trigger point dry needling along with sham ultrasound and group B $(n=20)$ received sham dry needling along with sham ultrasound for 1 week. The pain was measured by the numeric pain rating scale (NPRS), which is the most commonly used measure of pain intensity in clinical and research settings. ${ }^{15}$

NPRS has excellent test-retest reliability and validity with high application, as it is clinically easy to apply and time-saving (-Fig. 1). ${ }^{16}$

\section{Intervention Protocol for Group A: Experimental Group/Trigger Point Dry Needling}

The patient's position was in prone lying. The therapist palpated and marked the lumbar and pelvic girdle area for the four most painful trigger points to be used for dry needling. Targeted trigger points were in paraspinal, piriformis, hamstring, and calf muscles. Area of trigger point was disinfected with a cotton swab of isopropyl solution. Patients were briefed about the procedure, and appropriate dry needles were selected as per the targeted trigger point location. Needle with guide tube was taped quickly and inserted into the muscle to hit a trigger point. Care was taken not to damage surrounding neurovascular structures. Twitch response may elicit while procedure. Dynamic needling procedures were followed by performing the piston motion of the needle. The needle remained in situ for 2 minutes. ${ }^{17}$ Posttrigger point needling, sham ultrasound was applied in the lumbar area for 5 minutes. Patients were advised for a cold pack twice a day for 10 minutes following treatment to minimize postneedling soreness.

\section{Intervention Protocol for Group B: Control Group/Sham Dry Needling}

For group B subjects, trigger point needling was not done, and sham treatment was given by just tapping a needle on the skin. The rest of the procedure was the same as experimental group $\mathrm{A}$.

In addition to the above treatment, both group subjects were explained about back care strategies and good ergonomics along with the encouragement of activities like walking within their pain limit.

\section{0-10 NUMERIC PAIN RATING SCALE}

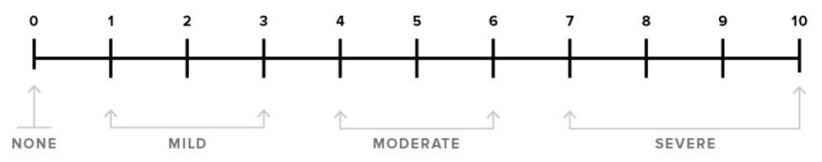

Fig. 1 Numeric pain rating scale (NPRS). 


\section{Data Analysis}

Data was managed into an Excel spreadsheet to form a master chart, and the IBM SPSS software platform was used for analysis.

\section{Results}

Forty female homemakers in the age group of 40 to 60 years were included in the study. For study purposes, two equal groups were made (-Fig. 2 ; - Table 1 ).

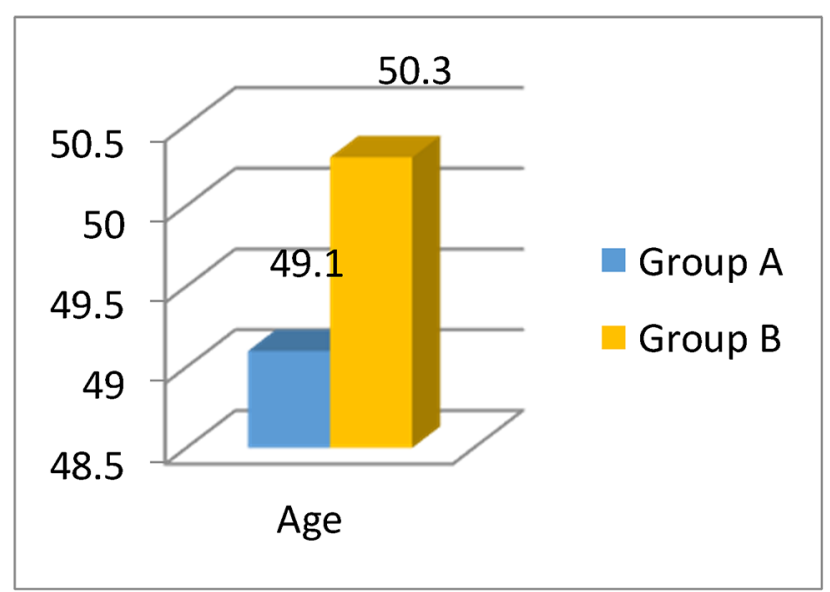

Fig. 2 Mean age (in years) of study participants in group A and group $B$.
There was no statistically significant difference between the mean ages of study participants in either of the groups (-Fig. 3; - Table 2).

There was no statistically significant difference between the preintervention pain scores of study participants in either of the groups (-Fig. 4; - Table 3 ).

There was a statistically significant difference between the mean pre- and postscores of both the groups $(p=0.001$ and

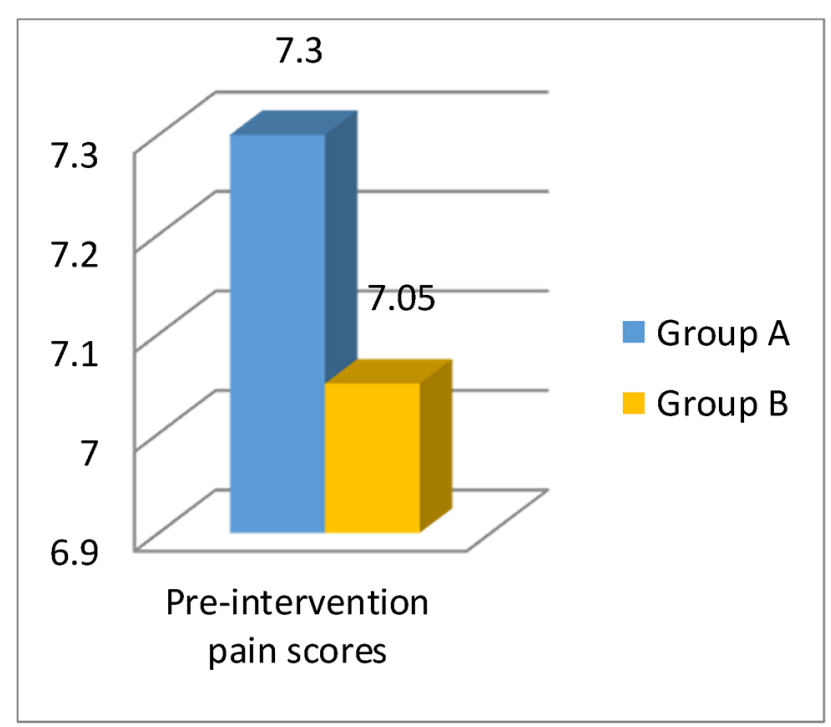

Fig. 3 Mean preintervention pain scores of study participants of group A and group B.

Table 1 Comparison of mean age (in years) of study participants between the two groups

\begin{tabular}{|l|l|l|l|l|l|l|l|}
\hline & Group & $\mathbf{N}$ & Mean & SD & df & t & Significance \\
\hline \multirow{2}{*}{ Age } & Group A & 20 & 49.1 & 7.225 & 38 & 0.548 & $p=0.587$ \\
\cline { 2 - 8 } & Group B & 20 & 50.3 & 7.371 & & & NS \\
\hline
\end{tabular}

Abbreviations: NS, not significant using independent $t$-test; SD, standard deviation.

Note: Level of significance at $p<0.05$.

Table 2 Comparison of mean preintervention scores between the two groups

\begin{tabular}{|l|l|l|l|l|l|l|l|}
\hline & Group & $\mathbf{N}$ & Mean & SD & df & t & Significance \\
\hline Pre & Group A & 20 & 7.3 & 1.593 & 38 & -0.52 & $p=0.606$ \\
\hline Post & Group B & 20 & 7.05 & 1.276 & & & NS \\
\hline
\end{tabular}

Abbreviations: NS, not significant using independent $t$-test; SD, standard deviation.

Note: Level of significance at $p<0.05$.

Table 3 Mean differences between pre- and postpain scores (NPRS) of two groups

\begin{tabular}{|l|l|l|l|l|l|l|l|l|}
\hline Group & & $\mathbf{N}$ & Mean & SD & MD & df & t & Significance (2-tailed) \\
\hline \multirow{2}{*}{ Group A } & Pre & 20 & 7.3 & 1.593 & 4.8 & 19 & 21.354 & $p=0.001^{\text {a }}$ \\
\cline { 2 - 10 } & Post & 20 & 2.5 & 0.946 & & & & \\
\hline \multirow{2}{*}{ Group B } & Pre & 20 & 7.05 & 1.276 & 1 & 19 & 2.703 & $p=0.014^{\mathrm{b}}$ \\
\cline { 2 - 10 } & Post & 20 & 6.05 & 1.099 & & & & \\
\hline
\end{tabular}

Abbreviations: MD, mean difference; SD, standard deviation.

Note: Level of significance at $p<0.05$.

aStatistically significant at $p<0.01$.

bStatistically significant at $p<0.05$ using paired "t" test. 


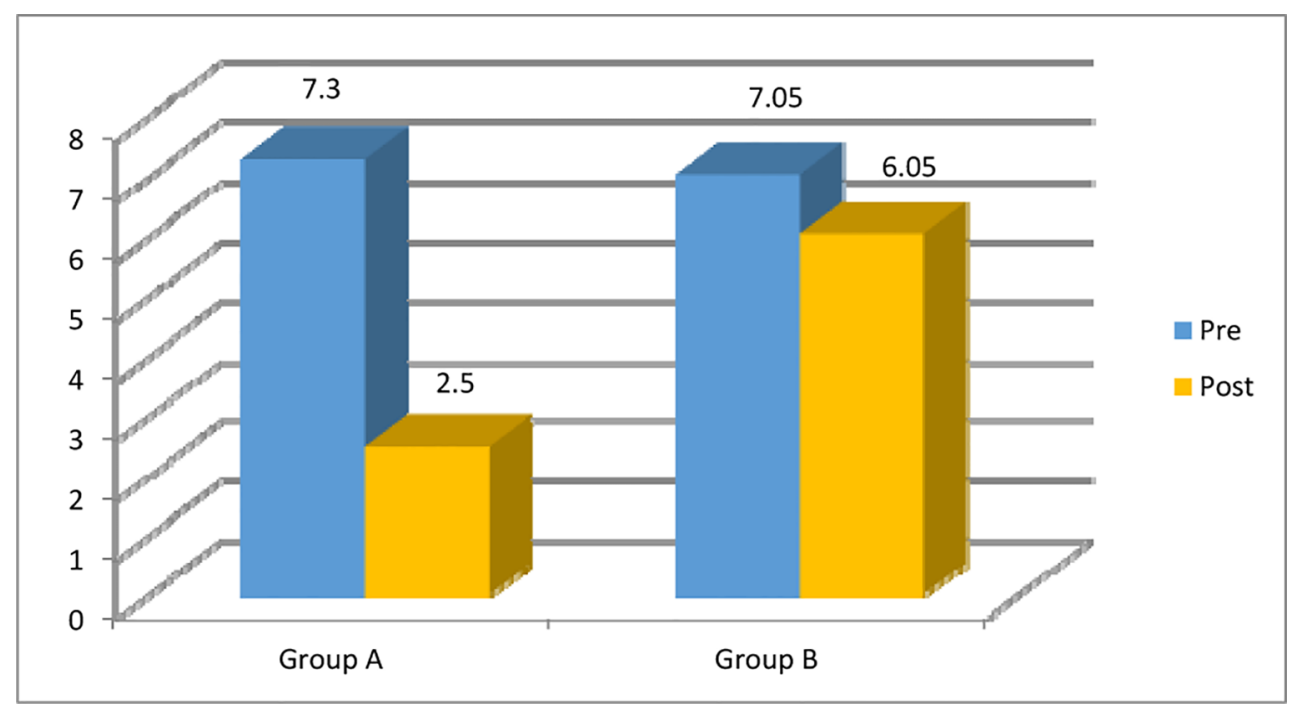

Fig. 4 Mean pre- and postintervention pain scores (numeric pain rating scale [NPRS]) observed among study participants in group A and group B.

$p=0.014$ ). However, the reduction in pain scores was statistically more significant in group A (decrease by $65.7 \%$ ) than group $B$ (decrease by $14.1 \%$ ). Therefore, the intervention provided to group $A$ was more effective than the intervention provided to group B study participants.

\section{Discussion}

Study results confirm trigger point dry needling as an effective and safe method of physiotherapy pain management for lumbosacral radiculopathy in homemakers The detailed mechanism behind dry needling is beyond the scope of this study, but we can definitely assume that dry needle neutralizes trigger points by breaking pain-spasm-pain cycle; also, there is the release of inflammatory mediators which hastens the healing process. Dry needling removes the pain signals from trigger points and improves the acetylcholine levels at the motor endplates which, in turn, improves overall tissue healing, pain, and function. Many other mechanical, chemical/cellular, electrophysiological, and neurophysiologic effects occur at the peripheral and central levels which are unclear. ${ }^{18}$ Trigger point dry needling was also found effective in managing pain related to the neck and shoulders in the medium term. ${ }^{19}$

Various studies are found to have effective results of trigger point dry needling in managing various neuromuscular pains.

Even though much evidence conforms that trigger point dry needling is effective in reducing neuromuscular pain, a great deal remains unknown about how the technique works.

It is not recommended to consider the mechanism of acupuncture to be the same for trigger point dry needling, as many different aspects are involved in the trigger point dry needling like pathophysiology of myofascial trigger points, the taut band, local ischemia and hypoxia, and peripheral and central sensitization. ${ }^{20}$
More research is needed if the full potential of trigger point dry needling is to be understood.

\section{Limitations and Future Scope of the Study}

Trigger point palpation and trigger point dry needling application is a skill-based subjective technique, so its application and results may vary from one individual to another, but proper training and hands-on practice can improve skills.

These results can be tested against different populations and with larger numbers; also, long-term effects need to be tested.

Trigger point dry needling with electric stimulation can enhance results further.

\section{Conclusion}

The study concluded that the trigger point dry needling technique is effective in decreasing the pain in subjects with lumbar radiculopathy, which is associated with myofascial trigger points.

\section{Conflict of Interest}

None declared.

\section{References}

1 Berry JA, Elia C, Saini HS, Miulli DE. A review of lumbar radiculopathy, diagnosis, and treatment. Cureus 2019;11(10):e5934

2 Schoenfeld AJ, Laughlin M, Bader JO, Bono CM. Characterization of the incidence and risk factors for the development of lumbar radiculopathy. J Spinal Disord Tech 2012;25(3):163-167

3 Tarulli AW, Raynor EM. Lumbosacral radiculopathy. Neurol Clin 2007;25(2):387-405

4 Bratt JM, Franzi LM, Linderholm AL, O'Roark EM, Kenyon NJ, Last JA. Arginase inhibition in airways from normal and nitric oxide synthase 2-knockout mice exposed to ovalbumin. Toxicol Appl Pharmacol 2010;242(1):1-8 
5 Tough EA, White AR, Richards S, Campbell J. Variability of criteria used to diagnose myofascial trigger point pain syndrome-evidence from a review of the literature. Clin J Pain 2007;23(3):278-286

6 Sari H, Akarirmak U, Uludag M. Active myofascial trigger points might be more frequent in patients with cervical radiculopathy. Eur J Phys Rehabil Med 2012;48(2):237-244

7 Alvarez DJ, Rockwell PG. Trigger points: diagnosis and management. Am Fam Physician 2002;65(4):653-660

8 Saeidian SR, Pipelzadeh MR, Rasras S, Zeinali M. Effect of trigger point injection on lumbosacral radiculopathy source. Anesth Pain Med 2014;4(4):e15500

9 Narvani AA, Tsiridis E, Kendall S, Chaudhuri R, Thomas P. A preliminary report on prevalence of acetabular labrum tears in sports patients with groin pain. Knee Surg Sports Traumatol Arthrosc 2003;11(6):403-408

10 Dunning J, Butts R, Mourad F, Young I, Flannagan S, Perreault T. Dry needling: a literature review with implications for clinical practice guidelines. Phys Ther Rev 2014;19(4):252-265

11 Unverzagt C, Berglund K, Thomas JJ. Dry needling for myofascial trigger point pain: a clinical commentary. Int J Sports Phys Ther 2015;10(3):402-418

12 Uygur E, Aktaş B, Özkut A, Erinç S, Yilmazoglu EG. Dry needling in lateral epicondylitis: a prospective controlled study. Int Orthop 2017;41(11):2321-2325
13 Camino Willhuber GO, Piuzzi NS, Straight Leg Raise Test. Treasure Island, Florida: StatPearls Publishing; 2021

14 Daniel WW, Biostatistics: A Foundation for Analysis in the Health Sciences. Hoboken: John Wiley \& Sons, Inc; 1999

15 Ferreira-Valente MA, Pais-Ribeiro JL, Jensen MP. Validity of four pain intensity rating scales. Pain 2011;152(10):2399-2404

16 Alghadir AH, Anwer S, Iqbal A, Iqbal ZA. Test-retest reliability, validity, and minimum detectable change of visual analog, numerical rating, and verbal rating scales for measurement of osteoarthritic knee pain. J Pain Res 2018;11:851-856

17 Acupuncture, Trigger Points and Musculoskeletal Pain - 3rd Edition. Available at: https://www.elsevier.com/books/ acupuncture-trigger-points-and-musculoskeletal-pain/ baldry/978-0-443-06644-3. Accessed August 25, 2021

18 Dommerholt J. Dry needling - peripheral and central considerations. J Manual Manip Ther 2011;19(4):223-227

19 Liu L, Huang QM, Liu QG, et al. . Effectiveness of dry needling for myofascial trigger points associated with neck and shoulder pain: a systematic review and meta-analysis. Arch Phys Med Rehabil 2015;96(5):944-955

20 Cagnie B, Dewitte V, Barbe T, Timmermans F, Delrue N, Meeus M. Physiologic effects of dry needling. Curr Pain Headache Rep 2013;17(8):348 